\title{
Estudos de Casos Hipertextuais: Rumo a uma Inovação no Método Harvard de Ensino de Gestão
}

\author{
Marcos Cerqueira Lima
}

\section{Resumo}

Adaptado ao ensino de gestores há quase um século, o método Harvard de estudos de casos é hoje amplamente adotado em escolas de Administração em todo o mundo. Este artigo propõe que as novas tecnologias de comunicação e informação oferecem oportunidade de enriquecer tal metodologia com recursos como interatividade dinâmica e colaboração assíncrona. Para tanto, são discutidas as principais características das interfaces hipertextuais e o caráter revolucionário da Internet como ferramenta educacional. No tocante ao método de estudos de casos, especificamente, argumenta-se que interfaces hipertextuais possibilitam uma forma inovadora de representar múltiplas perspectivas de análise das situações-problemas típicas de domínios de conhecimento pouco estruturados, conforme propõe a Teoria da Flexibilidade Cognitiva. É descrito, por fim, como estas características foram incorporadas ao Projeto Aplicado de Novas Tecnologias para Estudos de Casos Online - Panteon, uma interface para criação e diagnóstico de casos hipertextuais. O protótipo desta ferramenta de aprendizagem está em fase de testes, tanto em escolas de gestão quanto em organizações.

Palavras-chaves: método Harvard de estudos de casos; novas tecnologias de comunicação e informação; interfaces hipertextuais.

\section{Abstract}

Since it has been adapted to the teaching of managerial practice almost a century ago, the Harvard method of case studies is widely used in business schools all around the world. This article argues that new technologies of communication and information offer an opportunity to enrich such method with dynamically interactive resources and asynchronous collaboration. In order to attain such goal, the main characteristics of hypertextual interfaces are analysed, as well as the revolutionary potential of the Internet as a learning aid. As to the case method, specifically, the author argues that hypertextual interfaces facilitate an innovative way of representing multiple perspectives on the analysis of typical problem-situations found in ill-structured knowledge domains, as proposed by the Cognitive Flexibility Theory. He also describes how these characteristics have been built into the Applied Project of New Technologies for Online Case Studies - Panteon, an interface for creating and diagnosing hypertextual cases. Its prototype is currently being tested as a learning tool both in business schools and business organizations.

Key words: Harvard case study method; new technologies of communication and information; hypertextual interfaces. 


\section{A Era do Conhecimento e o Ensino de Gestão}

Vivemos supostamente na Sociedade da Informação. A produção de conhecimento nunca dependeu tanto do processamento crítico e analítico de informações, cada vez mais abundantes e dinâmicas (Burbules e Callister, 2000). Mais do que nunca, portanto, é necessário desenvolver em futuros profissionais de gestão o que se pode chamar de competência informacional (informational literacy) ou a "capacidade de utilizar uma gama de ferramentas de informação como fonte primária de elaboração de soluções” (Isaac, 2001, p. 144). De fato, tais ferramentas difundem-se rapidamente pelo mundo corporativo, afetando drasticamente os processos de tomada de decisão e os sistemas de informação que lhes dão suporte. As novas tecnologias da informação e da comunicação tornam visivelmente mais flexíveis e dinâmicos os processos gerenciais. Com a difusão crescente dos sistemas de informação, profissionais de gestão tendem a substituir a calculadora pela planilha eletrônica, os arquivos de papel pelos bancos de dados e os memorandos pelo uso de correio eletrônico. A gestão de recursos tende a ser feita por sistemas de planejamento empresarial; o atendimento ao cliente deverá ser crescentemente vinculado a sistemas de gestão de relacionamento e a relação com os fornecedores tende a ser monitorada por sistemas de gestão da cadeia de suprimentos (Lima, 2002).

Nas escolas de gestão, contudo, é raro ainda o uso de metodologias especialmente desenvolvidas com base nas possibilidades cognitivas dos novos meios (Naumes e Naumes, 1999). De fato, desde a invenção de Gutenberg, o avanço das formas de cognição tem-se dado sobretudo com base no pensamento linear inerente à tecnologia do papel impresso (Preston, 2001). Conforme McLuhan (1964, p. 228), ““um lugar para cada coisa e cada coisa no seu lugar’ não é apenas um princípio para o tipógrafo dispor suas fontes de tipos, mas um programa de largo âmbito para a organização do conhecimento e da ação a partir do século XVI”.

Esta herança linear da tecnologia impressa nas salas de aula de gestão parece ter sido pouco afetada pela revolução nos escritórios (Sandholtz, 1996). O conceito de conhecimento enquanto mero acúmulo de informações disciplinares e inertes reflete-se não apenas nos métodos tradicionais de ensino, mas sobretudo nas formas de avaliação. Ao invés de incorporar critérios que estimulem a capacidade de estabelecer relações analíticas, formular hipóteses e conceber alternativas a problemas complexos, as avaliações de alunos de gestão são fundamentalmente voltadas para aferir a capacidade de memorização conceitual. Jonassen e Carr (2000, p. 166) recentemente analisaram testes aplicados em 
disciplinas centrais de escolas de Administração norte-americanas e concluíram que

“65\% das questões (todas de múltipla escolha) mediam a capacidade de lembrança, memorização ou conhecimento do que os estudantes eram ensinados nas aulas ou liam nos textos; 25\% estavam no nível puramente conceitual; e 10\% avaliavam a capacidade de pensamento de ordem superior (como inferir regras, princípios e implicações). Baseados em uma série de exames como esse, os professores de administração estão dispostos a certificar (por meio de um grau de bacharel) que os formandos estão aptos a conduzir negócios. A competência do gestor, contudo, está na sua capacidade de reconhecer oportunidades de aplicação dos conceitos a situações práticas do mundo real; isto requer um nível de compreensão que não é examinado ou praticado nos cursos expositivos das universidades”.

É patente, portanto, a necessidade de estabelecer uma visão complexa e interdisciplinar dos problemas organizacionais no processo de educação de gestores (Senge, 1990). Segundo Jonassen, a fim de lidar com os fenômenos crescentemente complexos da Sociedade da Informação, é preciso que o processo de tomada de decisão e resolução de problemas seja lastreado por competências críticas, tais como estabelecer conexões, analisar e avaliar, e competências criativas, tais como imaginar, elaborar e sintetizar. A este conjunto de competências ele chama "pensamento complexo" (Jonassen, 1996, p. 28). Para o autor, o uso de metodologias construtivistas de aprendizagem permite estimular simultaneamente o pensamento crítico (conhecimento reorganizado) e criativo (conhecimento gerado), com suas respectivas competências específicas (Lima, 2001). Por metodologias construtivistas ele entende aquelas que privilegiam ao mesmo tempo ação, reflexão e colaboração por parte do estudante, e que são situadas em contexto autêntico de aprendizagem (Jonassen et al., 1999).

Parece clara a importância dos elementos constitutivos do pensamento complexo e da aprendizagem construtivista para o profissional e para o estudante de gestão. Os chamados trabalhadores do conhecimento lidam com situações de tomada de decisão em que variáveis econômicas, políticas, psicológicas, sociais e financeiras afetam concomitantemente o mercado, exigindo do gestor não apenas a capacidade de conceber estratégias, mas de resolver problemas e tomar decisões complexas. Para atingir tal complexidade de raciocínio, conforme sugerido, é preciso estabelecer conexões entre os componentes críticos da tomada de decisão, analisando os contextos em que os problemas se apresentam e avaliando as conseqüências de possíveis intervenções. Por outro lado, cabe também ao gestor desenvolver a capacidade criativa de imaginar 
cenários futuros, elaborar soluções inovadoras e sintetizar os resultados obtidos de forma convincente, a fim de mobilizar os membros da organização na direção da estratégia concebida (Lima, 2002).

Ciente das limitações das aulas expositivas no tocante ao desenvolvimento do pensamento complexo em gestores, a Universidade de Harvard introduziu, há quase um século, um método até então empregado no ensino de Direito e Medicina: os estudos de casos. Trata-se de proposta pedagógica que parece atender tanto aos princípios construtivistas de aprendizagem ativa, reflexiva, colaborativa e autenticamente contextualizada, quanto aos desafios do modelo de pensamento complexo acima expostos. A próxima seção descreve as principais características do método Harvard de estudos de casos. Em seguida, propomos uma alternativa de enriquecimento do método, por meio do uso de novas tecnologias hipertextuais, cujas características de flexibilidade cognitiva podem potenciar ainda mais o desenvolvimento do pensamento complexo e da aprendizagem construtivista em gestores.

\section{O Método Tradicional de Estudos de Casos no Ensino}

Charles Gragg é considerado um dos pais do método Harvard (Bhatti, 1985). Segundo sua definição, um caso é tipicamente um registro de uma situação organizacional com os fatos que a circundam, bem como as opiniões dos atores envolvidos, com base nas quais devem ser tomadas decisões (Gragg, 1954). Esta apresentação geralmente se dá sob a forma de relato (Roesch, 1997), com um ou poucos pontos de vista sobre os fatos narrados (Pemberton, 1995). Tipicamente, estudos de casos incluem uma cronologia de eventos significativos no desenvolvimento organizacional, sumários de custos importantes, informações sobre os competidores e o mercado e opiniões de empregados (Edge e Coleman, 1982). Casos variam amplamente quanto ao formato e conteúdo. As situações representadas são baseadas em eventos reais, ainda que disfarçados para preservar o anonimato de pessoas e instituições envolvidas. Alguns apresentam uma retrospectiva dos fracassos de determinada estratégia, enquanto oferecem ao leitor a oportunidade de sugerir medidas mais eficazes. Outros requerem a identificação do problema central em uma situação complexa e a sugestão de como resolvê-lo. Outros ainda solicitam que seja escolhido um curso de ação, incluindo a previsão das suas conseqüências. Todos os casos têm em comum o fato de serem um meio de análise de dados, identificação de problemas e tomada de decisão (May, 1984). 
A análise de caso geralmente consiste em selecionar um ou diversos problemas centrais da situação apresentada, organizar os fatos mais relevantes deste entorno de problemas, selecionar alternativas de solução, ponderar prós e contras de cada alternativa e recomendar a opção que pareça trazer a melhor relação custo/benefício (Schnelle, 1967). Segundo Ronstadt (1993), a análise efetiva de um caso freqüentemente faz uso de uma combinação de três abordagens: a sistêmica, a comportamental e a decisorial. Para o autor, uma não é necessariamente superior à outra; o bom analista de caso saberá usar esta ou aquela, conforme seja mais adequada aos fatores envolvidos. A abordagem sistêmica privilegia as entradas, processos e saídas do sistema gerencial, buscando identificar problemas em cada etapa; a comportamental atém-se aos elementos das relações humanas envolvidas nos processos administrativos; a decisorial é aquela em que modelos de análise específicos são usados como suporte para avaliação de cursos alternativos de ação.

Estudos de casos permitem desenvolver as seguintes competências relacionadas ao pensamento complexo em gestão: (1) análise e pensamento crítico; (2) identificação de problemas, tomada de decisão e busca de soluções; (3) discernimento entre possíveis alternativas de ação; (4) manipulação de hipóteses e inferências; (5) aplicação prática de teorias de gestão (Bhatti, 1985). Estas características confirmam os elementos críticos e criativos do modelo de pensamento complexo citado anteriormente. Estão presentes também os elementos de aprendizagem construtivista propostos por Jonassen, na medida em que é requisitado dos estudantes participação constante, reflexão acerca das suas inferências e conclusões e colaboração no processo de diagnóstico coletivo e durante os debates em sala de aula. Por último, tais atividades se processam em torno de uma organização específica e seus problemas concretos, o que fornece aos estudantes um contexto autêntico de aprendizagem.

Tais elementos de aprendizagem são também encontrados, em menor grau, nas aulas expositivas tradicionais. De fato, é difícil - senão impossível - enxergar como a educação pode ser feita, sobretudo nos seus níveis mais elementares, sem algum tipo de ensino instrutivista (Howe e Berv, 2000). Desta forma, o método de estudos de casos não se propõe absolutamente a substituir a exposição teórica, mas a complementá-la. Limitações de custo, tempo e escopo tornam imprescindíveis aulas expositivas, quando o objetivo é meramente a instrumentalização conceitual.

Comparando estudos de casos pioneiros (Copeland, 1954; Culliton, 1954; Dewing, 1954; Raymond, 1955) com os atuais (Naumes e Naumes, 1999; Oliveira, 2000; Rocha e Mello, 2000), nota-se que os elementos fundamentais do método se mantiveram virtualmente inalterados. Conforme será discutido a seguir, as novas 
características cognitivas das tecnologias de comunicação e informação apresentam uma oportunidade de adaptação do método supradescrito a meios mais flexíveis e dinâmicos do que o texto impresso, em que sempre se baseou.

\section{Interfaces Hipertextuais e a Teoria da Flexibilidade Cognitiva}

Os grandes saltos evolutivos na história das civilizações são freqüentemente associados a inovações na tecnologia de comunicação (Lévy, 1999). A essência dessa idéia, a que Deibert (1998) chama de medium theory, está refletida no pensamento de teóricos como Harold Adam Innis e Marshall McLuhan. Na década de 60 , estes autores propuseram que os meios de comunicação são em grande parte determinantes das formas de organização social. Assim, a prevalência do homo sapiens sobre os Homens de Neandertal teria coincidido aproximadamente com o desenvolvimento da linguagem oral na nossa espécie, há 35 mil anos; o surgimento das primeiras Cidades-Estados na Suméria, em torno do século 35 a.C., coincide com a invenção da escrita e a subseqüente viabilidade do controle contábil; o apogeu da cultura helênica, entre o sétimo e terceiro século a.C., coincide com a difusão do alfabeto fonêmico; mais recentemente, a Renascença na Europa dos séculos XV e XVI coincide com o desenvolvimento da tipografia móvel por Gutenberg (Deibert, 1998). O autor sugere que estas não seriam meras coincidências, mas uma relação de meios de comunicação como provocadores de transformações na forma de cognição humana, subseqüentemente, na forma de organização das sociedades. Neste sentido, argumenta, as interfaces hipertextuais podem vir a ser o próximo veículo de transformação da epistemologia social da nossa era.

Que são estas interfaces e que é que as torna tão revolucionárias? Muito embora interfaces hipertextuais façam parte do dia-a-dia de qualquer pessoa medianamente educada no mundo moderno, nem sempre nos damos conta dos elementos inovadores a elas associados. Discutiremos alguns destes elementos como suporte do argumento de que estamos, de fato, diante da possibilidade histórica de desenvolver novas ferramentas de suporte à cognição de gestores.

\section{Navegação Hipertextual por meio de Interfaces Gráficas}

Hipertexto é definido como tecnologia de informação, consistindo em blocos individuais de texto e elos eletrônicos interconectados (Landow, 1994), ou um texto que usa as capacidades de acesso aleatório do computador para quebrar a 
seqüência narrativa linear do papel (Sewell, 1990), ou ainda como sistema com texto ativo, que permite ao usuário estabelecer suas próprias rotas de navegação (Preece, 1993). No hipertexto, portanto, a apresentação das informações varia a cada leitura, conforme opções de busca por palavra-chave ou seqüência de cliques do mouse. A grande maioria das páginas na Internet se encaixa, por definição, no formato hipertextual: a própria linguagem em que são programadas chama-se Hypertext Mark-up Language ou HTML e o protocolo que as disponibiliza nos navegadores chama-se Hypertext Transfer Protocol ou HTTP. O hipertexto é considerado por alguns como subconjunto de uma categoria maior chamada hipermídia (Norton e Sprague, 2001), a qual, além de texto convencional, permite representar figuras, vídeo, som etc. Entretanto, como a palavra texto, na sua acepção mais ampla, abarca qualquer forma de representação simbólica (Barthes, 1993), a distinção entre hipertexto e hipermídia é supérflua.

Sem estruturação mínima e contexto inicial, a interpretação de hipertextos podese tornar impossível (Burbules e Callister, 2000). Para navegar em hipertextos, portanto, é necessário utilizar interfaces que medeiem operações de transcodificação e gestão de fluxos de informações. Assim, uma interface gráfica consiste nos elementos visuais que, manipulados, permitem navegar por miríades de informações de um ambiente hipertextual (Stansberry, 1998). Os programas chamados de browsers ou navegadores da Internet, como Microsoft Internet Explorer ou Netscape Navigator, são exemplos de interfaces gráficas. Cada página Web geralmente traz sua subinterface própria, incluindo menus interativos, gráficos de navegação (setas, mapas etc.), a fim de tornar mais estruturado e disponível o seu conteúdo específico.

Assim como as técnicas de paginação, indexação e referências cruzadas revolucionaram a capacidade de registrar e obter informações impressas (Thimbleby, 1992), as interfaces hipertextuais revolucionam a forma como armazenamos e recuperamos informações digitais. Interfaces gráficas podem facilitar o acesso remoto a redes de bancos de dados, por exemplo, proporcionando meios de categorização de cada elemento armazenado ou recuperado. Graças a esta característica, os nódulos de informação podem ser acessados não apenas por elos estáticos mas também por categorias de análise (Müllhäuser, 1990). Nesta linha, pode-se dizer que tais interfaces, em termos das possibilidades de recombinações e de associações em uma rede de textos, estão para a impressão, assim como esta esteve para os manuscritos em papiro ou pergaminho (Lévy, 1993).

\section{Hipertextos de Flexibilidade Cognitiva}

Por ser a hipertextualidade um conceito relativamente recente, ainda não se pôde avaliar todas as suas possibilidades pedagógicas. A chamada Teoria da 
Flexibilidade Cognitiva (TFC) é pioneira na discussão do uso de interfaces hipertextuais aplicadas ao método de estudos de casos. Originalmente, foi concebida por um grupo de pesquisadores da Universidade de Illinois, para ajudar médicos a entender melhor os matizes envolvidos no diagnóstico de problemas cardiovasculares (Spiro et al., 1992). A TFC propõe que, para domínios de conhecimento pouco estruturados, tais como História, Administração ou Medicina, os métodos de ensino tradicionais, baseados em prescrições genéricas para problemas simplificados, não ajudam os alunos a entender como transformar o seu conhecimento declarativo (informações inertes, acumuladas sem elos estruturais) em conhecimento procedimental (capacidade de resolver novos problemas). Trata-se de perspectiva construtivista de aprendizagem, portanto compatível com os princípios de aprendizagem ativa, reflexiva, colaborativa e contextualizada revisados anteriormente.

Segundo a TFC, a fim de compreender a complexidade do mundo real, aprendizes devem ser capazes de entender e reconciliar subjetivamente diferentes interpretações de uma mesma realidade. Em domínios pouco estruturados do conhecimento, a natureza multifacetada de uma situação-problema real se apresentará somente por meio do uso de múltiplos esquemas, conceitos e perspectivas de análise (Jonassen et al., 1997). Mais especificamente, o modelo de flexibilidade cognitiva propõe que, em tais domínios pouco estruturados, as seguintes premissas são verdadeiras: (1) a complexidade e as grandes variações caso a caso representam obstáculo à aquisição de conhecimentos por métodos tradicionais de ensino; (2) a supersimplificação típica de alguns métodos tradicionais de ensino impedem o aprendiz de entender a complexidade das situaçõesproblemas envolvidas, dificultando a sua capacidade de transferir o conhecimento adquirido para novas situações; (3) a aprendizagem por casos, analisados a partir de múltiplas perspectivas, favorece a aprendizagem e a sua aplicação em situações novas; (4) para que os estudantes desenvolvam flexibilidade cognitiva é preciso que os ambientes de aprendizagem repliquem tal complexidade e permitam a abordagem multidimensional a estudos de casos realistas; (5) o computador, devido à sua flexibilidade de representações hipertextuais, é adequado à construção de tais ambientes de aprendizagem (Spiro et al., 1992).

Os pressupostos da Teoria da Flexibilidade Cognitiva dão origem a interfaces de aprendizagem chamadas Hipertextos de Flexibilidade Cognitiva (HFC). Interfaces tipo HFC permitem ao usuário vasculhar diversos minicasos com um contexto comum, utilizando múltiplas perspectivas de análise. Deste processo de perpassar o território (criss-crossing of a knowledge landscape) em várias direções, resulta uma percepção multifacetada e complexa dos fenômenos estudados (Spiro e Jehng, 1990). Assim como os estudos de casos tradicionais, Hipertextos de Flexibilidade Cognitiva também proporcionam papel ativo, reflexivo 
e colaborativo aos participantes, em ambiente tão autêntico quanto os do método Harvard. Como naquele método, os estudantes devem estruturar o seu próprio entendimento das questões. Não lhes é dito quais respostas ou perspectivas são corretas. Na medida em que tentam solucionar o problema, os estudantes constroem esquemas cognitivos complexos que correspondem a um savoir faire específico, não a mero amálgama de fatos desconexos, cuja utilidade futura é questionável .

Em comparação com o meio impresso dos casos convencionais, contudo, interfaces hipertextuais baseadas em bancos de dados apresentam pelo menos duas vantagens inerentes ao meio digital em que são abrigadas (Burbules e Callister, 2000): interatividade dinâmica e comunicação assíncrona. Para fins deste trabalho, definimos como interatividade dinâmica dois aspectos fundamentais dos hipertextos baseados em bancos de dados: filtragem dinâmica de dados e manipulação dinâmica de dados.

- Filtragem dinâmica de dados: possibilidade de organizar e reorganizar a seqüência em que o conteúdo é apresentado, conforme critérios de busca que o leitor achar mais convenientes para sua estratégia de navegação. Essa característica facilita estabelecer relações entre fragmentos dispersos de informações que, de outra forma, permaneceriam desconexos. Em um estudo de caso hipertextual, esta funcionalidade permite ao usuário, por exemplo, investigar todas as informações relativas a um departamento específico de uma empresa, ou referentes a uma única situação-problema, ou ainda concernindo determinada personagem.

Manipulação dinâmica de dados: possibilidade de armazenamento e recuperação de informações de acordo com critérios de busca que o leitor achar mais conveniente para sua estratégia de navegação. Assim, interfaces hipertextuais baseadas em bancos de dados, via Internet, são capazes de reter todas as informações registradas por seus usuários, permitindo a eles recuperálas a qualquer momento, desde que devidamente identificados por meio de senha pessoal. Graças a esta característica, o usuário que diagnostica um caso hipertextual pode digitar anotações em pontos específicos do seu percurso de análise, armazená-las de acordo com os elementos daquele contexto (por exemplo, a que personagem se referem as informações, sobre qual situaçãoproblema etc.) e mais tarde recuperá-las de forma categorizada. Tal funcionalidade não apenas enriquece as ferramentas de diagnóstico, mas sobretudo possibilita a autoria de casos hipertextuais, como será demonstrado na próxima seção deste trabalho.

Além dos dois componentes-chaves inerentes a qualquer sistema de bancos de dados, interfaces hipertextuais via Internet permitem que sua funcionalidade seja 
distribuída e à distância, graças à capacidade de comunicação assíncrona; esta ocorre quando emissor e receptor estão separados não apenas pelo espaço, mas também pelo tempo. Muito embora esta forma de comunicação seja tão antiga quanto a escrita e as práticas epistolares, as novas tecnologias de comunicação lhe acrescentam dinamismo sem precedentes. $\mathrm{O}$ e-mail, por exemplo, confere não somente velocidade, mas também contexto para a troca de mensagens. É possível responder laconicamente a trechos específicos da mensagem graças à facilidade de reprodução do texto original, por exemplo. Este recurso deu origem aos chamados fóruns de discussão na Web, que permitem organizar uma quantidade grande de informações conforme autor, assunto ou data. Via Internet, é possível a comunicação assíncrona de um-para-muitos ou muitos-para-muitos. Por conta destas características, tanto a criação quanto o diagnóstico de estudos de casos hipertextuais podem ser feitos à distância. Estudantes podem comparar seus diagnósticos com o de consultores especializados ou mesmo com os resultados obtidos por outros estudantes em outros Estados ou países.

O formato digital dos estudos de casos hipertextuais apresenta, ainda, alguns outros elementos secundários que o diferenciam dos textos impressos tradicionalmente distribuídos por Harvard. As possibilidades de representação, por exemplo, incluem o uso de fotos e figuras coloridas, som, vídeo e animações gráficas acessíveis por milhares de usuários simultaneamente (Naumes e Naumes, 1999). Ademais, ao contrário de produtos multimídia em CD-ROM, cuja fabricação e distribuição pode ser dispendiosa, a proliferação de conteúdos pela Internet é instantânea e ubíqua. Por fim, como é possível restringir a visualização das páginas com base em senhas do usuário, autores de casos têm o poder de determinar se seu produto pode ser visualizado por todos ou apenas por determinado grupo de pessoas, como os alunos de um curso ou funcionários de empresa específica.

Em suma, casos hipertextuais parecem oferecer pelo menos os mesmos benefícios do método tradicional, além de acrescentar características potencialmente enriquecedoras. A fim de avaliar o potencial de enriquecimento didático das características acima, está sendo atualmente testado, em uma escola de gestão, o protótipo de uma interface para criação e diagnóstico de estudos de casos hipertextuais. A seção a seguir descreve tal interface e apresenta elementos do seu design que embutem as referências teóricas discutidas.

\section{O Projeto Panteon}

O Panteon, acrônimo de Projeto Aplicado de Novas Tecnologias para Estudos de Casos Online, nasceu da seguinte pergunta: se, conforme a medium theory, a 
cada salto tecnológico corresponde de fato um ganho potencial na capacidade de cognição humana, como as novas tecnologias de comunicação e informação podem contribuir para o processo de ensino-aprendizagem de gestores? O projeto começou como simples proposta de criar um estudo de caso tradicional em CDROM, enriquecido com elementos multimídia como vídeo, som e animação gráfica. Essa idéia original evoluiu para o conceito de acesso a um banco de dados via Web, que permitisse a qualquer aluno de administração (ou professor, ou gestor profissional) criar seus próprios estudos de casos hipertextuais ou diagnosticar casos de terceiros. Embora já houvesse algumas experiências anteriores com hipertextos de flexibilidade cognitiva (Spiro et al., 1992; Jonassen e Carr, 2000; Lajoie e Azevedo, 2000; White et al., 2000), nenhuma delas tratava de estudos de casos para ensino de gestão. Além disso, pelo fato de serem apresentadas sob a forma de páginas estáticas (não baseadas em bancos de dados), estas experiências não ofereciam ao usuário a possibilidade de criação de estudos próprios de caso e o nível de interação durante o diagnóstico era relativamente baixo (isto é, não havia nessas interfaces a possibilidade de armazenar e recuperar informações de uma base de dados dinâmica). Salvo melhor conhecimento, o Panteon é hoje a única proposta de uso de páginas ativas, baseadas em bancos de dados, para criação e diagnóstico de estudos de casos organizacionais disponível online. Embora o protótipo esteja ainda em fase de testes, as suas características dinâmicas, descritas a seguir, já estão plenamente funcionais.

Ao acessar o site do Panteon - cujo protótipo está disponível no site da Escola de Administração da Universidade Federal da Bahia (UFBA), em www.adm.ufba.br/panteon - o visitante tem a opção de identificar-se como já cadastrado, providenciando login e senha, ou cadastrar-se como novo usuário. Uma vez identificado, o visitante tem a opção de criar um novo estudo de caso hipertextual ou diagnosticar um caso de terceiros, usando critérios de busca como palavras-chaves, autores ou instituição de origem. As subseções abaixo ilustram os procedimentos envolvidos tanto na criação como no diagnóstico de casos.

\section{Criando Estudos de Casos Hipertextuais com o Panteon}

A construção de um estudo de caso Panteon é feita com base em seis elementos: modelo de análise adotado, texto introdutório, estrutura organizacional, situaçõesproblemas, personagens envolvidas e percepções das personagens. Estes elementos podem ser criados a partir de entrevistas com participantes de uma organização real, ou com diversos representantes de determinado segmento empresarial, ou podem, ainda, ser completamente fictícios; para casos fictícios, sugere-se que a autoria seja feita por grupos de indivíduos cuja vivência de problemas reais ou cujas áreas de expertise se traduzam na caracterização 
verossímil de determinada realidade organizacional. A Figura 1 apresenta as etapas de criação, discutidas a seguir.

\section{Figura 1: Etapas de Criação de um Caso Hipertextual com o Panteon}

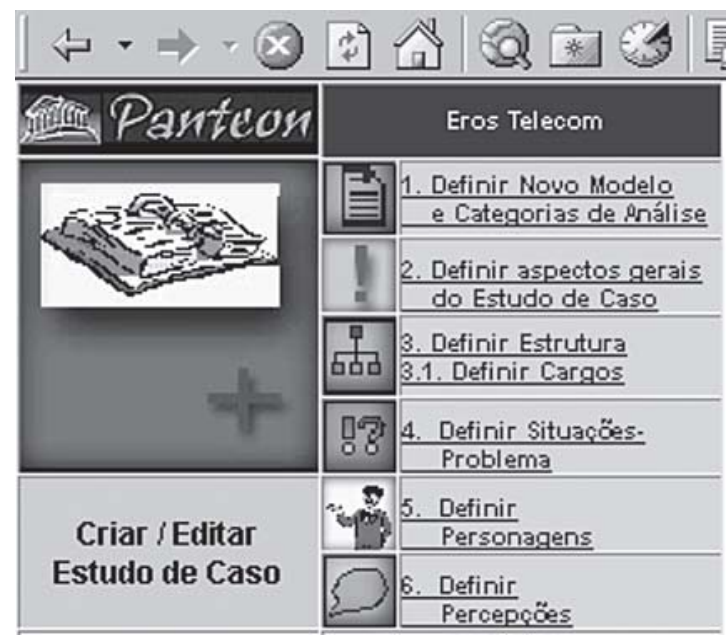

1. Modelo de análise adotado: por modelo entende-se determinado encadeamento heurístico de categorias de análise. O modelo PFOA (Kotler e Armstrong, 1993), por exemplo, tradicionalmente utilizado em estudos de casos, consiste em quatro categorias de análise: Potencialidades (fatores positivos controláveis pela empresa), Fragilidades (fatores negativos controláveis), Oportunidades (positivos não controláveis) e Ameaças (negativos não controláveis). Soluções com base neste modelo consistem em identificar e maximizar elementos P e O e identificar e minimizar elementos F e A. Em outro exemplo, o clássico modelo de rivalidade ampliada (Porter, 1991) pode ser descrito a partir de cinco categorias de análise: poder de barganha dos fornecedores, dos clientes, rivalidade interna, novos entrantes e substitutos. Autores podem criar seus próprios modelos de análise ou adotar modelos preestabelecidos por outros usuários. Para cada modelo está disponível uma apresentação tipo Microsoft PowerPoint, de modo a facilitar o entendimento das relações entre as categorias de análise e como o modelo pode ser utilizado no diagnóstico.

2. Aspectos genéricos e texto introdutório: aqui os autores devem descrever, em poucas páginas, o histórico da empresa, o cenário competitivo, a crise atual e/ou o dilema aparente, as principais personagens, a cultura organizacional, aspectos informais das redes internas e o que mais acharem necessário para a contextualização introdutória. 
3. Estrutura organizacional: os autores devem definir em quantas divisões (departamentos e subdepartamentos) se constitui a organização. A cada nova divisão criada (por exemplo, “marketing”, “finanças” etc.) é possível atribuir um nível de subdivisão (por exemplo, “promoção” e “logística”, “administrativo” e “contábil” etc). É preciso cadastrar também a nomenclatura de cargos utilizada pela empresa, como “diretor”, “vice-presidente”, “assistente” etc. A posição de certa personagem na hierarquia é definida pelo cargo associado ao departamento ou subdepartamento, como, por exemplo: "diretor” + “marketing” ou "assistente” + "produção” + "linha de calçados infantis”.

4. Situações-problemas: são parágrafos que detalham os principais problemas identificados no texto introdutório, tais como "entrada de um novo concorrente" ou “perda de competitividade no segmento Y”. Estas descrições podem ser acompanhadas de qualquer material de suporte da tomada de decisão correspondente (balanços, planilhas de custos, relatórios de vendas, artigos de jornais etc.).

5. Personagens: ao criar cada personagem, os autores devem atribuir-lhes nome, posição hierárquica (utilizando menus do tipo pull down, cujas opções serão dadas conforme estrutura organizacional previamente definida pelos próprios autores do caso), perfil psicológico e descrição funcional. Com base nas dezenas de fotos disponíveis no banco de dados, os autores devem ainda escolher um rosto para representar a personagem conforme o seu biótipo: idade, gênero, estilo de vestir etc.

6. Percepções das personagens: este é o ponto-chave para a construção de casos hipertextuais com o Panteon; a interface solicita dos autores que, para cada personagem, seja digitada uma percepção conforme cada situaçãoproblema na perspectiva de cada categoria de análise. Assim, por exemplo, o diretor de marketing (personagem) pode ter a seguinte percepção sobre uma ameaça (categoria de análise) associada à "entrada de novo concorrente" (situação-problema): "se não reagirmos imediatamente com redução de preços e aumento de qualidade, certamente teremos perda de fatias de mercado”. Naturalmente, nem todas as personagens precisam ter uma opinião sobre cada problema em todas as categorias de análise.

Conforme os princípios propostos de flexibilidade cognitiva, quanto mais pontos de vista sobre o mesmo aspecto de um domínio de conhecimento pouco estruturado, maior a capacidade de representar a complexidade inerente. Num estudo de caso minimamente complexo, se doze personagens emitem percepções sobre quatro situações-problemas de acordo com cada uma das cinco categorias de um modelo de análise qualquer, obtém-se, no máximo, um total de 240 parágrafos de 
percepções. Como nem todas as personagens terão necessariamente uma opinião sobre cada situação com base em todas as categorias de análise, este número pode ser significativamente reduzido; mas, ainda assim, restará mais de uma centena de opiniões a serem analisadas. É precisamente na navegação não-linear desta miríade de percepções que reside a complexidade de representação dos contextos em que os problemas organizacionais ocorrem; não baseados apenas em fatos objetivos, mas na subjetividade inerente aos múltiplos pontos de vista, com as suas contradições, complementaridades, redundâncias e ambigüidades.

\section{Diagnosticando Estudos de Casos Hipertextuais com o Panteon}

De volta às opções iniciais, imagine-se que um internauta não esteja interessado em criar seu próprio caso, mas em diagnosticar casos de marketing, envolvendo empresas de médio porte no setor têxtil. Ele digita estas palavras-chaves no motor de busca e recebe uma lista de casos que satisfazem aos critérios estabelecidos; as primeiras linhas descritivas do texto introdutório de cada caso lhe são apresentadas para facilitar a sua escolha. Ao clicar no caso escolhido, o usuário é levado à tela de diagnóstico, mostrada na Figura 2. O objetivo dos analistas é capturar e comentar, entre as dezenas de percepções disponíveis, aquelas que eles acharem mais relevantes em cada categoria de análise, com vistas a fundamentar a redação do seu diagnóstico final. Para tanto, devem percorrer as quatro etapas apresentadas na figura.

\section{Figura 2: Ferramentas de Diagnóstico de um Caso Hipertextual com o Panteon}

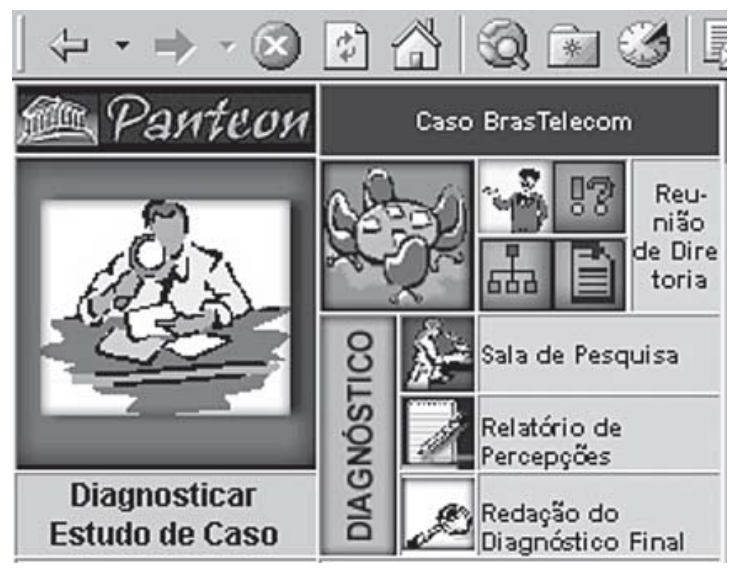

1. Reunião de diretoria: com um clique em cada um dos cinco ícones desta etapa, o usuário é apresentado ao texto introdutório do caso, ao modelo de análise adotado (apresentação em PowerPoint), à estrutura organizacional, 
às situações-problemas e às personagens. Pode-se revisitar este ambiente a qualquer momento do transcurso do diagnóstico, clicando em um dos cinco ícones referidos.

2. Sala de pesquisa: após familiarizar-se com os aspectos gerais do caso, o usuário deve escolher entre seis alternativas de análise das percepções disponíveis: por palavra-chave (por exemplo, todas as percepções que contenham a palavra "custo"); por cargo (por exemplo, todas as percepções dos diretores, ou das secretárias); por departamento (por exemplo, tudo o que os membros do departamento de marketing pensam sobre os problemas); por personagem (por exemplo, todas as opiniões de Carlos Azevinho, diretor de marketing); por categoria de análise (por exemplo, todas as "ameaças" ou todas as "fragilidades"); ou por situação-problema (por exemplo, tudo sobre "novo concorrente”). Cada opção de busca tem o seu próprio menu tipo pulldown, onde estão listados os elementos cadastrados pelo autor, exceto a busca por palavra-chave, que aceita quaisquer caracteres digitados. Ao selecionar qualquer destas opções, o usuário verá uma lista de fotografias de personagens que satisfazem aos critérios de busca, com seus respectivos nomes e posições (cargo e departamento), bem como suas opiniões. Cada opinião refere-se a determinada situação-problema, de acordo com determinada categoria de análise pertinente. Uma vez obtida a lista com as opiniões desejadas, o usuário deverá capturar as que achar mais relevantes para o seu diagnóstico. Para isso deve clicar sobre o ícone do bloco de anotações que acompanha cada percepção (abaixo da foto da personagem); ao identificar um clique sobre o ícone, o programa copia para o banco de dados pessoal do usuário a percepção selecionada e todos os dados associados (personagem que a emitiu, posição hierárquica, situação-problema associada, categoria de análise etc.), conforme seta indicativa na Figura 3. Na sub-interface chamada PantPad, o usuário poderá digitar comentários individuais para cada percepção capturada. Estas percepções e anotações subsidiarão o seu diagnóstico final mais adiante. No exemplo da Figura 3, a usuária Ana Luiza acabou de capturar e comentar uma percepção da personagem Adelaide Martins (chefe de produção).

3. Relatório de percepções coletadas: aqui o usuário pode verificar quais percepções coletou até o momento com o PantPad e classificá-las instantaneamente por personagem, por departamento, por situação-problema ou por categoria de análise, como for mais conveniente. Estas reorganizações dinâmicas dos dados permitem identificar zonas pouco exploradas do banco de dados. Se, por exemplo, o analista constatar que ainda não tem percepções suficientes em determinada categoria de análise ou situação-problema, pode retornar à sala de pesquisa e capturar opiniões que preencham essas lacunas. 


\section{Figura 3: Captura de Percepções e Digitação de Comentários Pessoais durante Diagnóstico com o Panteon}

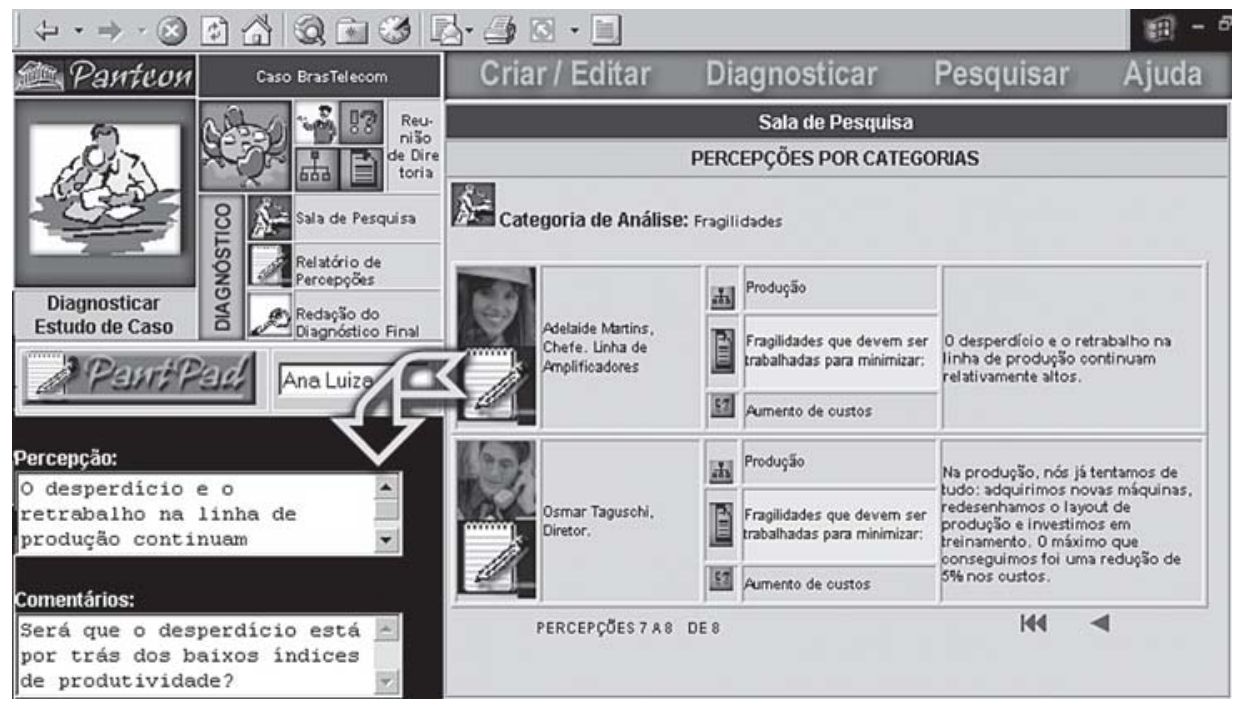

4. Redação do diagnóstico final: para cada combinação de categoria de análise e situação problema (por exemplo, "potencialidades” associadas a "novo mercado"), a interface apresenta as percepções coletadas correspondentes. Para cada combinação, o usuário deve redigir um diagnóstico parcial, baseado nas respectivas percepções e anotações disponíveis. É preciso produzir uma síntese pessoal diante das contradições, complementaridades, redundâncias e ambigüidades das percepções coletadas, argumentando por que determinadas percepções são mais bem fundamentadas do que outras. A argumentação a favor de determinadas percepções em detrimento de outras, ou em favor de uma síntese entre as percepções disponíveis, deve ser julgada com base nas competências do pensamento complexo, apresentadas anteriormente. Isso envolve a análise dos recursos objetivos disponíveis (planilhas, relatórios), capacidade de síntese, de estabelecer conexões e de resolver problemas. Por fim, a cada diagnóstico devem corresponder uma ou mais propostas de planos de ação. Se por exemplo, o caso envolve três situações-problemas e quatro categorias de análise, pelo menos doze mini-diagnósticos com respectivos planos de ação devem ser produzidos. Os planos de ação devem também ser julgados conforme as competências de pensamento complexo do estudante, tais como a capacidade de conceber hipóteses, avaliar alternativas e tomar decisões.

A parte mais rica da metodologia proposta não está no diagnóstico final ou nos planos de ação sugeridos por cada grupo, mas na negociação entre grupos em 
busca de uma síntese coletiva. Esta parte ocorre longe dos laboratórios de informática, na sala de aula convencional. Imagine-se uma situação de ensinoaprendizagem em que, na mesma sala, cinco grupos foram formados para diagnosticar um caso proposto. Com a ajuda de um canhão de projeção multimídia, cada grupo pode demonstrar os seus diagnósticos e planos de ação, lastreados em determinadas percepções que capturou e comentou previamente em seu próprio banco de dados pessoal. Como cada grupo terá utilizado estratégias diferentes de navegação pela multiplicidade de percepções disponíveis, é natural que (como acontece em organizações reais) o olhar de uma equipe se tenha detido em aspectos negligenciados por outra. Por conta desta dissonância, esperase obter calorosas discussões em sala, mediadas pelo professor, em que os grupos devem convencer-se mutuamente da solidez dos seus argumentos e produzir uma síntese coletiva. Tal síntese, espera-se, será mais rica do que cada análise individual. O produto da negociação intergrupal pode, por sua vez, ser comparado ao resultado obtido por outras equipes separadas pela distância e/ou pelo tempo; pode-se, por exemplo, navegar passo a passo no processo de diagnóstico dos próprios autores do caso ou de consultores especializados, nas percepções que eles julgaram mais relevantes, nos seus comentários em cada percepção etc.

\section{Considerações Finais}

Há diferenças metodológicas significativas entre o Panteon e os casos Harvard. Primeiramente, modelos de análise são usados geralmente a posteriori nos casos tradicionais, como ferramenta de diagnóstico. No Panteon, os modelos aparecem como estrutura necessária à coleta de percepções em entrevistas com os gestores, que servirão de base para a construção do caso. Em segundo lugar, também a identificação dos problemas é apriorística na metodologia Panteon. No método tradicional, identificar os problemas implicados no texto é geralmente parte do exercício de diagnóstico do estudante. Este artifício de pré-identificação dos problemas permite articulá-los com as categorias de análise do modelo, dando origem à complexidade das múltiplas percepções acerca dos mesmos problemas. Tal multiplicidade de percepções, por seu turno, constitui um terceiro elemento inteiramente novo, ausente na apresentação tradicional de problemas do método Harvard. Neste sentido, o Panteon propõe não apenas uma inovação no medium como também na estrutura de apresentação dos casos, de modo a adaptá-los aos ambientes hipertextuais e aproveitar todo o seu potencial. O meio impresso não tem como proporcionar ao leitor o dinamismo de acesso às dezenas de percepções da forma como o fazem os casos do projeto Panteon. O projeto em andamento tem por finalidade testar a hipótese de que tal flexibilidade, inerente às interfaces 
hipertextuais, pode enriquecer competências críticas e criativas no processo cognitivo dos estudantes de administração.

O estabelecimento a priori de um modelo específico é ao mesmo tempo virtude e limitação da metodologia proposta. Por um lado, esta determinação de um modelo força os estudantes a utilizá-lo sistematicamente ao longo de todo o diagnóstico; por outro lado, limita o processo de análise do caso, restringindo parcialmente as possibilidades de diagnóstico com o Panteon. Ainda que esta limitação da nova interface seja minimizada pelo uso de múltiplos modelos de análise para o mesmo caso, o método Harvard parece mais adequado, quando se quer desenvolver no estudante a capacidade de construir seus próprios modelos ou escolher, entre os modelos existentes, qual o mais apropriado para o diagnóstico de determinado caso. Uma forma alternativa de desenvolver esta competência nos estudantes com o Panteon é incentivá-los a criar seus próprios estudos de casos hipertextuais; na condição de autores, os alunos serão igualmente forçados a criar modelos de análise ou escolher entre modelos existentes o que melhor se aplica ao contexto organizacional que desejam explorar.

Os testes do protótipo da interface Panteon serão concluídos até o final do ano letivo de 2003. Espera-se que a versão final do site esteja aberta ao acesso das instituições de ensino de gestão em língua portuguesa, em meados do ano letivo de 2004. Nesse entretempo, uma equipe de professores vem-se dedicando à criação dos primeiros casos hipertextuais para a interface. Está sendo elaborado um livro sobre a metodologia de criação e diagnóstico de estudos de casos hipertextuais com o Panteon, via Internet, cujo objetivo é estimular outros professores, alunos ou gestores profissionais de língua portuguesa a contribuir com seus próprios casos e diagnósticos para o crescimento do banco de dados online. Paralelamente, está sendo concluída uma versão em inglês da interface para uso da comunidade internacional de educação de gestores.

Para além do uso didático, pretende-se que o Panteon venha a ser também uma ferramenta de gestão do conhecimento em empresas de médio e grande porte. Com o uso da interface, é possível a colaboradores nos vários níveis hierárquicos de uma organização expressar suas percepções em torno de situações-problemas concretamente vivenciadas, de forma anônima ou aberta. Para tanto o processo de criação e diagnóstico de casos pelo site do Panteon na Internet pode ser restringido por senha para impedir acesso externo. Os colaboradores podem então criar personagens que reflitam os seus próprios pontos de vista, não necessariamente identificando estas personagens com sua posição na empresa. De vários pontos da rede interna, percepções podem ser representadas em várias categorias de análise, permitindo enxergar os problemas na perspectiva de clientes insatisfeitos com o atendimento, de fornecedores 
preocupados com a ineficiência logística ou mesmo de um insuspeito faxineiro da linha de produção, que pode ser personagem criada, por exemplo, pelo técnico de garantia da qualidade especialmente para ilustrar um princípio simples de manutenção. A coleta e análise estruturada de tal pluralismo de percepções pode ser bastante facilitada pelas referidas características de acesso dinâmico aos bancos de dados das interfaces hipertextuais. Com o uso do método ao longo do tempo, as empresas podem ter à sua disposição um banco de dados com a evolução das percepções dos seus colaboradores sobre os problemas organizacionais mais críticos, de acordo com múltiplos modelos de análise.

À guisa de conclusão constata-se que, embora interfaces hipertextuais como os browsers de navegação na Internet já sejam lugar comum nos escritórios em todo o mundo, pouco se tem especulado ainda sobre como utilizá-las para a educação de gestores ou mesmo para a gestão do conhecimento organizacional. Estudantes e profissionais em todo o planeta utilizam a Internet meramente como fonte de informações, desprezando o seu potencial como ferramenta cognitiva. Este artigo buscou demonstrar que é possível e oportuno estimular estudantes a desempenhar, por meio das características ímpares do novo meio, as mesmas competências informacionais que são requeridas dos novos profissionais de gestão no contexto complexo em que são tomadas as decisões na Era da Informação.

\section{REFERÊnCIAS BibliográficAS}

BARTHES, R.

Mitologias. São Paulo: Bertrand Brasil, 1993.

BHATTI, K. M.

A case study of the case study method. Peshawar: Pakistani Academy for Rural Development, 1985.

BURBULES, N.;

CALLISTER, $\mathrm{T}$.

Watch IT: the risks and promises of information technologies for education. Boulder: Westview Press, 2000.
COPELAND, M. T.

The genesis of the case method in business instruction. In: MCNAIR, M. P. (Org.). The case method at the Harvard Business School. New York: McGraw-Hill, 1954.

CULLITON, J. W.

Writing business cases. In: MCNAIR, M. P. (Org.). The case method at the Harvard Business School. New York: McGraw-Hill, 1954. 
DEIBERT, R. J.

Parchment, printing, and hypermedia: communication in world order transformation. New York: Columbia University Press, 1998.

DEWING, A. S.

An introduction to the use of cases. In: MCNAIR, M. P. (Org.). The case method at the Harvard Business School. New York: McGraw-Hill, 1954.

EDGE, A. G.;

COLEMAN, D. R.

The guide to case analysis and reporting. Honolulu: System Logistics, 1982.

GRAGG, C. I.

Because wisdom can't be told. In: MCNAIR, M. P. (Org.). The case method at the Harvard Business School. New York: McGraw-Hill, 1954.

HOWE, K.; BERV, J.

Constructing constructivism, epistemological and pedagogical. In: PHILliPS, D. C. (Org.). Constructivism in education: opinions and second opinions on controversial issues. Chicago: National Society for the Study of Education, 2000.

ISAAC, J. R.

Identifying educational core competencies for the information age. In: TAYLOR, H.; HORGENBIRK, P. (Orgs.). Information and communication technologies in education: the school of the future. Boston: Kluwer Academic Publisher: 2001.

JONASSEN, D.

Computers in the classrom. Englewood Cliffs, NJ: Prentice Hall, 1996.

JONASSEN, D.;

CARR, C.

Mindtools: affording multiple knowledge representations for learning. In: LAJOIE, S. (Org.). Computers as cognitive tools. Hillsdale, NJ: Lawrence Erlbaum, 2000. v. II.

JONASSEN, D. et al.

Cognitive flexibility hypertexts on the web: engaging learners in meaning making. In: KHAN, B. H. (Org.). Web-based instruction. Englewood Cliffs, NJ: Educational Technology Publishing, 1997.

Learning with technology: a constructivist perspective. Englewood Cliffs, NJ: Prentice Hall, 1999.

KOTLER, P.; ARMSTRONG, G.

Princípios de marketing. Rio de Janeiro: Prentice Hall, 1993. 
LAJOIE, S.;

AZEVEDO, R.

Cognitive tools for medical informatics. In: LAJOIE, S.

(Org.). Computers as cognitive tools. Hillsdale, NJ: Lawrence Erlbaum, 2000. v. II.

LANDOW, G.

What's a critic to do? Critical theory in the age of hypertext. In: - Hypertext theory. Baltimore: The Johns Hopkins Press, 1994.

LÉVY, P.

Cibercultura. São Paulo: Editora 34, 1999.

LIMA, M.

Teoria da flexibilidade cognitiva e a autoria de estudos de casos hipertextuais em ambientes de aprendizagem construtivistas: projeto aplicado de novas tecnologias para a educação online. In: CONGRESSO BRASILEIRO DA COMUNICAÇÃO, XXIV., 2001, Campo Grande. Anais... [S.l.: s.n.], 2001.

Ambientes de aprendizagem organizacional mediados por computador: o projeto aplicado de novas tecnologias para educação on-line. In: CARDOSO, C. (Org.). Comunicação organizacional hoje: novos desafios, novas perspectivas. Salvador: Unibahia, 2002.
MAY, S.

Case studies in business: a skills-based approach. London: Pitman Publishing, 1984.

\section{MCLUHAN, M.}

Os meios de comunicação como extensão do homem. São Paulo: Cultrix, 1964.

\section{MÜLLHÄUSER, M.}

Hyperinformation requirements for an integrated authoring/ learning environment. In: JONASSEN, D.; MANDL, H. (Org.). Designing hypermedia for learning. Berlim: SpringerVerlag, 1990.

NAUMES, W.;

NAUMES, M. J.

The art and craft of case writing. London: Sage Publications, 1999.

NORTON, P.; SPRAGUE, D.

Technology for teaching. Neeham Heights: Allyn \& Bacon, 2001.

OLIVEIRA, J.

Cases. São Paulo: Érica, 2000.

PEMBERTON, J. M.

Bringing ethics to life: case study method and ARMA International's code of professional responsibility. Records Management Quarterly, v. 29, p. 56-58, Jan. 1995. 
PORTER, M. E.

Estratégia competitiva: técnicas para análise de indústrias e da concorrência. Rio de Janeiro: Campus, 1991.

\section{PREECE, J.}

Hypermedia, multimedia and human factors. In: LATCHEM, C.; WILLIAMSON, J.; HENDERSON-LANCETT, L. (Org.). Interactive multimedia: practice and promise. London: Kogan Page, 1993.

\section{PRESTON, C.}

Lifelong learning in the electronic age. In: LEASK, M. (Org.). Issues in teaching using ICT. London: Routledge Falmer, 2001.

RAYMOND, T. C.

Problems in business administration: analysis by the case method. New York: McGraw-Hill, 1955.

ROCHA, A. da;

MELLO, R. C. de.

Marketing de serviços: casos brasileiros. São Paulo: Atlas, 2000.

\section{ROESCH, S.}

O relato de casos para o ensino com apoio na literatura. Organizações \& Sociedade, n. 8, v. 4, p. 119-141, 1997.

\section{RONSTADT, R.}

The art of case analysis. Wayland: Lord Publishing, 1993.
SANDHOLTZ, J. H.

Teaching with technology. New York: Teachers College Press, 1996.

SCHNELLE, K. E.

Case analysis and business problem solving. New York: McGraw-Hill, 1967.

SENGE, $\mathrm{P}$.

A quinta disciplina: arte, teoria e prática da organização de aprendizagem. São Paulo: Best Seller, 1990.

SEWELL, D. F.

New tools for new minds: a cognitive perspective on the use of computers with young children. New York: St. Martin's Press, 1990.

SPIRO, R. J. et al.

Knowledge representation, content specification, and the development of skill in situation specific knowledge assembly: some constructivist issues as they relate to cognitive flexibility theory and hypertext. In: DUFFY, T.; JONASSEN, D. (Orgs.). Constructivism and the technology of instruction: a conversation. Hillsdale, NJ: LEA, 1992. 
SPIRO, R. J.;

JEHNG, J. C.

Cognitive flexibility and hypertext: theory and technology for nonlinear and multidimensional transversal of complex subject matter. In: NIX, D.; SPIRO, R. J. (Orgs.). Cognition, education, and multimedia: exploring ideas in high technology. Hillsdale, NJ: Lawrence Erlbaum, 1990.

STANSBERRY, D.

Labyrinths - the art of interactive writing \& design: content development for new media. Belmont: Wadsworth Publishing Company, 1998.
THIMBLEBY, $\mathrm{H}$.

Heuristics for cognitive tools. In: KOMMERS, P.; JONASSEN, D.; MAYES, J. T. (Orgs.). Cognitive tools for learning. Berlin: Springer-Verlag, 1992.

WHITE, B. et al.

Facilitating students' inquiry learning and metacognitive development through modifiable software advisers. In: LAJOIE, S. (Org.). Computers as cognitive tools. Hillsdale, NJ: Lawrence Erlbaum, 2000. v. II. 